\title{
Voluntary corporate climate initiatives and regulatory threat
}

\section{Dragan Ilić ${ }^{1,2}$. Janick Christian Mollet ${ }^{1,3}$}

Accepted: 18 August 2021/Published online: 27 October 2021

(C) The Author(s) 2021

\begin{abstract}
Does participation in voluntary environmental initiatives affect firm value? We take a closer look at the Chicago Climate Exchange (CCX) and the Climate Leaders (CL), two US initiatives to curb carbon emissions that were operating during a decisive regulatory event. In 2009 the Waxman-Markey Bill surprisingly passed the House of Representatives and brought the US economy a big step closer to a nationwide $\mathrm{CO}_{2}$ emission trading system. With an event study we assess how the stock market valued membership in the initiatives when the likelihood of $\mathrm{CO}_{2}$ regulation unexpectedly increased. Our findings suggest that only membership in the market-based CCX was considered beneficial for a mandated carbon market. This is consistent with research that equity-based regulation through financial markets can help economies favor clean industries over dirty ones. We interpret the empirical results in a simple model. Adding earlier market reactions to the firms' membership announcements, the model implies that the market had been betting on a mandatory emission trading system all along.
\end{abstract}

Keywords Regulation · Voluntary markets · Permit markets · Financial markets · Climate change $\cdot$ Greenhouse gas emissions $\cdot \mathrm{CO}_{2} \cdot$ Corporate social responsibility $\cdot$ Shareholder wealth $\cdot$ Equity

JEL Classification G38 · Q53 · Q54 · Q58

Dragan Ilić
dragan.ilic@unibas.ch
Janick Christian Mollet
janick.mollet@polynomics.ch

1 ETH Zürich, CER Center of Economic Research, ZUE F11, Zürichbergstrasse 18, 8092, Zürich, Switzerland

2 Faculty of Business and Economics, University of Basel, Peter Merian-Weg 6, 4002 Basel, Switzerland

3 Polynomics, Olten, Switzerland 


\section{Introduction}

In 2016 the Paris Agreement took effect to mitigate the environmental impact of greenhouse gases. To this date, 190 states and the European Union have ratified the treaty, covering about $97 \%$ of global emissions. Among them are the US, along with China the leading nation in greenhouse gas emissions.

According to the agreement, each country is free to choose its strategy to mitigate global warming. So far, the US has lacked federal legislation addressing carbon emissions on firm level. ${ }^{1}$ Although now largely forgotten, it already had a serious go at implementing carbon pricing on 26 June 2009, when the US House of Representatives, with a razor-thin margin, passed H.R. 2454, the "American Clean Energy and Security Act of 2009". Dubbed the Waxman-Markey Bill, this act aimed to cap $\mathrm{CO}_{2}$ emissions in the US with an emission trading system. The passage of this bill caught the public off guard. Even though the bill was gradually defeated later on, its success in the House of Representatives unexpectedly and credibly increased the likelihood of federal carbon legislation in the US. Suddenly it seemed more likely than not that the government would mandate a costly emission trading system in the near future.

The passage of the bill conveyed new information to the stock markets and affected different firms differently. In this paper, we test the hypothesis that firms participating in binding voluntary environmental initiatives were at an advantage at that time. Such a membership could be understood as transmitting to investors a signal of resilience against the bill's impending carbon cost. This signal of resilience could stem from the initiatives' learning environment that had helped improve the corporate footprint or it could stem from self-selected entry into the initiatives by those firms that had a prior advantage in mitigation. To test this hypothesis, we empirically investigate whether being a member in such an initiative pays off in testing times, that is, whether membership is rewarded by the market when the threat of regulation suddenly increases. Specifically, we conduct an event study to compare the implications of corporate membership in two distinct major $\mathrm{CO}_{2}$ abating programs that were operating during the passage of the Waxman-Markey Bill; the Chicago Climate Exchange (CCX) and the Climate Leaders (CL). We test whether membership in the CCX and CL initiatives was immediately rewarded by the stock market when it adjusted to the unanticipated rise in likelihood of federal $\mathrm{CO}_{2}$ legislation. ${ }^{2}$ The two programs differed in design. The CL initiative pursued a broad, non-market-based approach with support from the US government. The CCX program, a cap-and-trade system, was market-based and relied on independent verification. As it happens, a similar mechanism was foreseen in the bill.

\footnotetext{
${ }^{1}$ There are regional efforts: In 2013 California introduced a cap-and-trade program. However, the large number of allocated pollution permits has lead to a price decay. Other initiatives encompass several states. The Regional Greenhouse Gas Initiative aims to reduce greenhouse gases in nine states in the northeast and is limited to large fossil fuel power plants.

${ }^{2}$ It stands to reason that the passage of the Waxman-Markey Bill had been partially anticipated. But the passage of the bill had been uncertain and suddenly increased the probability of legislation, which lends itself to an event study. We elaborate on this argument in Sections 2.1, 3, and 6.
} 
The comparative stock market reaction for CCX and CL program members to the Waxman-Markey Bill is this paper's main analysis. In order to round up the picture and gain a more conclusive interpretation about the stock market's assessment, we compare in a complementary event study how the earlier announcements to join these programs had been gaged. The direction of a possible reaction in stock price to the membership announcements is not readily obvious. On the one hand, such a costly new engagement could be perceived as detrimental from an investor's point of view because joining might yield no net benefit for preparing for future regulation or because the new membership might not offer any signal value.

On the other hand, investors might embrace such membership announcements despite the cost of joining. The abatement knowledge that stands to be gained in the initiative could be perceived as positive. Or investors might interpret joining as an informative signal about self-selection: Only firms that are actually "fit" to withstand future environmental regulation and want to signal that would find it in their interest to join the costly initiative. Stock market reactions upon their membership announcements would then be favorable through the revelation of valuable private information.

In the complementary event study we analyze the membership announcement effect for CCX firms only. For CL firms, this very question has already been answered in another event study by Fisher-Vanden and Thorburn (2011). Our paper employs the same identification and statistical inference method, so we can integrate their results into our analysis. In contrast, we cannot make use of existing research on CCX membership reactions by Gans and Hintermann (2013) because of a difference in study design. We proceed to elaborate on the findings of our two event studies - the Waxman-Markey Bill and the membership announcements - in a very simple theoretical framework of market expectations and reduced compliance costs from voluntary initiatives in light of regulatory pressure.

The results suggest that investors deemed CCX members to be better prepared to cushion the blow of a carbon market. Conservative estimates suggest that, on average, stock prices of CCX members experienced positive abnormal returns of $0.82 \%$ in reaction to the passage of the Waxman-Markey Bill. CL members did not exhibit any abnormal returns during that event. In our complementary event study, we do not find any measurable market response for the earlier announcements of membership to the CCX. In contrast, Fisher-Vanden and Thorburn found negative reactions for CL announcements. Within the context of the theoretical framework, these results suggest that the market had already expected a carbon market during the earlier period of membership announcements. Different empirical model specifications show that industry effects explain a substantial part of the market reaction. The market seemed to predict that an mandatory emission trading system would affect different industries differently.

The rest of the paper is structured as follows. The next section provides background information on the Waxman-Markey Bill, the two voluntary corporate climate initiatives, and the related literature. It also puts forth the theoretical framework we will use to interpret our findings. Section 3 lays out the event study methodology, followed by the description of our data in Section 4. The results of the two event studies are presented and discussed in Section 5, and the last section concludes. 


\section{Background}

\subsection{Waxman-Markey}

H.R. 2454, the "American Clean Energy and Security Act of 2009" was a bill to propose, among other things, the introduction of a mandatory cap-and-trade system in the US. The bill, also known as the Waxman-Markey Bill, would regulate the emission of greenhouse gases, in particular $\mathrm{CO}_{2}$. Over the next 40 years carbon emissions were to be increasingly capped up to $83 \%$ of 2005 levels. Allocated with $\mathrm{CO}_{2}$ allowances, regulated firms would be free to trade their pollution rights at market prices. $^{3}$

After months of negotiations, on Friday 26 June 2009 at 7:17 p.m. the House of Representatives narrowly passed the bill by a vote of 219 to 212 . For the first time in US history a cap-and-trade legislation passed through either House of Congress. The passage had been uncertain up to that day and stirred up emotional responses afterwards, pointing towards a controversial and rather unexpected outcome. Actual market data support the impression of the passing as a partial surprise. ${ }^{4}$ Complete surprises are rare in the political realm. Even so, event studies are useful in that they can measure the effect of becoming sure about an event that had been only partially anticipated (Langer and Lemoine 2020). In Section 5 we identify industry specific effects which, too, are in accord with the not fully expected nature of the passage of the bill and its impact on the macroeconomy.

With the exception of Senator Lindsay Graham joining the Senate's climate efforts on 4 November 2009, support for the bill was fading out over the months following the passage in the House of Representatives (Meng 2017). With Lindsay Graham dropping his support on 23 April 2010, the Democrats in the Senate followed suit and on 22 July 2010 abandoned the bill.

\subsection{Chicago climate exchange and climate leaders}

Two major initiatives to curb greenhouse gas emissions in the US were operating during the passage of the Waxman-Markey Bill. The so-called Chicago Climate Exchange $(\mathrm{CCX})$ was a trade platform for $\mathrm{CO}_{2}$ certificates. Its members agreed to a reduction goal and independent verification of their efforts. The second initiative was the Climate Leaders (CL) program, which was an industry-government partnership to help firms reduce emissions of greenhouse gases. Although these two initiatives

\footnotetext{
${ }^{3}$ The cap-and-trade system constituted the most prominent element of the legislation, but the contents of the bill extend beyond this market instrument.

${ }^{4}$ From 2009 to 2010, the online trading exchange Intrade hosted a prediction market contract on the prospects of a US cap-and-trade system titled "A cap and trade system for emissions trading to be established before midnight ET on 31 Dec 2010". The passage of the bill was the only event that raised the expected probability above 50\%. The data from Intrade were accessed on 20 June 2021 on http:// intrade-archive.appspot.com/contract.jsp?contract=674142. For more on the value of prediction markets for event studies, see Snowberg et al. (2011).
} 
pursued the same goal, their approaches differed in fundamental aspects. We present each initiative in more detail.

In 2003, the CCX started trading operations of the first cap-and-trade system in North America with 13 charter members that made voluntary but legally binding commitments to reduce six different types of greenhouse gas emissions. ${ }^{5}$ The CCX was characterized by a market mechanism; a platform where prices formed and allowances were exchanged. As part of its cap-and-trade scheme the CCX relied on a carbon offset program. Over the course of its operation the exchange had around 400 members with annual membership fees ranging from 1,000-60,000 USD, depending on firm size and membership type. ${ }^{6}$ In November 2010, the CCX announced that it would shut down the program, arguing that firms were no longer interested in trading emission credits in the absence of government legislation (Financial Times 2010).

Figure 1 in the Appendix shows the daily traded volume in metrics tons and the price per metric ton on the CCX marketplace from 2004 to 2010. Most of the trading took place in 2008 and 2009, with more than 3.5 millions metric tons being traded each year. During the CCX lifespan the price ranged from near zero to 7.5 Dollars. From 2005 to 2008, the average price was about 3 Dollars, before dropping to around 1 Dollar in 2009 and eventually fading out in 2010.

Formed in 2002, the Climate Leaders Greenhouse Gas Inventory Protocol (CL) is the second major voluntary initiative that operated during the passage of the Waxman-Markey Bill. CL members did not restrict themselves to $\mathrm{CO}_{2}$ reductions but dedicated themselves to six main greenhouse gas emissions. The CL program was an industry-government partnership initiated by the US Environmental Protection Agency (EPA) that worked with companies to develop comprehensive climate change strategies. Upon becoming a partner, the EPA assisted each company in developing inventory and inventory management plans. Partners then set a corporate-wide domestic or global five to ten year greenhouse gas reduction goal and reported annual inventory data to the EPA (Tonkonogy and Oliva 2007).

Upon engagement, the EPA evaluated the proposed reduction goals from all partners, requiring a reduction compared to the projected GHG performance of the sector. Partners were also allowed to develop their own mitigation offset projects or purchase certified mandatory or voluntary GHG reductions, provided that the projects adhered to approved EPA methodologies. Participating members pledged to a realistic reduction goal within a five to ten year time frame. That pledge, however, was not under close scrutiny through independent verification. According to the EPA, partners were sure to receive high level recognition via participation in meetings, public outreach, or press events (Tonkonogy and Oliva 2007). Members also profited from the EPA's technical assistance. On 15 September 152010 the EPA announced their decision to cease operation of the CL program in light of new political developments.

\footnotetext{
${ }^{5}$ CCX Fact Sheet, November 2011. https://www.theice.com/publicdocs/ccx/CCX_Fact_Sheet.pdf, visited on 20 June 2021

${ }^{6}$ https://web.archive.org/web/20161227130746/http://co2offsetresearch.org/policy/CCX.html, visited on 20 June 2021
} 
The two programs differed along two important dimensions. First, the CCX constituted a marketplace for trading $\mathrm{CO}_{2}$ emission certificates, whereas the CL program was an industry-government partnership initiated by the EPA without a focus on market mechanisms. Second, unlike the CCX, the CL did not rely on mandatory third party verification, rendering their environmental efforts less traceable. Lack of traceability can have significant consequences. In a field experiment, Telle (2013) finds evidence that firms under-report environmental violations in self-audits. To external parties, then, the CL might have radiated less credibility than the CCX.

\subsection{Related literature}

The literature has identified a variety of economic motives for firms to join voluntary initiatives, some of which are based on imperfect markets (for an overview, see Khanna 2002; Portney 2008). These motives can be roughly divided into market motives and political motives (Fleckinger and Glachant 2011).

Political motives make a solid case for joining the CCX or the CL. Lyon and Maxwell $(2003,2008)$ argue that by participating in voluntary environmental initiatives firms seek to preempt or shape future public policies. This motive rationalizes voluntary participation as preparation for some expected legislation. If there is reason to believe that future environmental legislation will impose costly regulation upon firms, it might be reasonable to dampen the impact of such a future shock by adjusting corporate behavior today and by preparing voluntarily. A smooth path towards the expected extent of the regulation entails lower overall costs than a sudden adjustment.

Private information could be another motive to join an initiative. From such a perspective, voluntary participation can be understood as a signaling mechanism to the market that one's cost to lower $\mathrm{CO}_{2}$ emissions are comparatively low. Because membership in the CCX or the CL is a costly endeavor, only low-cost types would find it in their interest to join. Joining an initiative for these motives can relay advantageous information to the market. Unexpected changes in the probability of impending legislation and the consequences for firm value provide a testing ground for this hypothesis.

There is previous work on our question. Gans and Hintermann (2013) assess membership announcement effects and Waxman-Markey Bill effects for CCX firms based on a panel with monthly stock data using event-dummies. They conclude that for both events, the market reacted highly favorably. However, there are two drawbacks to their research design. First, Gans and Hintermann's CCX sample was not screened for contemporaneous confounding events affecting firm value. Second, instead of daily data they employ a difference-in-differences framework with monthly stock returns.

Such a research design is at odds with the established understanding and inference how markets adjust to new information. Markets absorb new information quickly, making event studies the method of choice for assessing this reaction. One cannot isolate the effect of CCX membership and make a reliable statement about whether the estimated returns in Gans and Hintermann are causally attributable to the events in question. Our paper addresses these issues and integrates the existing CL membership announcement effects from Fisher-Vanden and Thorburn (2011), whose research design dovetails with ours. 
There is a large body of evidence that supports the view that a sudden increase in the likelihood of future regulation is taken into account as new information by the market. ${ }^{7}$ For instance, Bowen et al. (1983) and Hill and Schneeweis (1983) suggest that the nuclear incident at the Three Mile Island facility in 1979 altered the investors' perception of future regulation by resulting in a sudden drop in stock prices for electric utility firms, in particular for those who were invested in nuclear power. The chemical disaster in Bhopal in 1984 had a similar effect. Once the extent of the tragedy had become clear, the market seemingly anticipated tighter regulation for the entire chemical industry (Blacconiere and Patten 1994). Unexpected changes in regulatory direction can work as shocks, too. The sudden proposal by President George Bush in 1989 to revise the Clean Air Act triggered a drop in stock prices of notoriously polluting coal firms (Kahn and Knittel 2003; Freedman and Patten 2004). And recently, the unexpected reaction of the German government to the Fukushima incident affected energy companies' shareholder wealth (Betzer et al. 2013).

Yet some firms seem to fare better in harsh times. There is evidence that voluntary engagement and subsequent verified disclosure is rewarded by the market when external shocks materialize. For example, more extensively disclosing firms were at an advantage after the chemical leak in Bhopal (Blacconiere and Patten 1994). The same held true after the sudden legislation of the Superfund Amendments and Reauthorization Act in the US in 1986 to handle sites contaminated with hazardous substances and pollutants (Blacconiere and Northcut 1997). And firms that were part of the Carbon Disclosure Project experienced an increase in shareholder value when Russia unexpectedly ratified the Kyoto Protocol in 2004 (Kim and Lyon 2011).

\subsection{Theoretical framework}

A combined comparison of the two initiatives for membership announcements effects on the one hand and upon the Waxman-Markey Bill on the other hand may yield a more coherent understanding of market expectations and the market's prescribed values of membership. Linking the two threads through time yields predictions that can support or refute different hypotheses about market expectations. To this end, we put forth a very simple theoretical framework about market reactions to membership announcements to voluntary initiatives and a subsequent rise in regulatory threat. The framework illustrates how connecting two dimensions - initiative type and (chronological) event type - can increase our confidence in the interpretation of observable stock price adjustments.

In a first phase, consider market reactions upon membership announcements to costly voluntary initiatives designed (for the sake of the argument) to curb $\mathrm{CO}_{2}$ emissions. The market might consider joining an initiative a positive signal. Membership might be inherently useful by reducing compliance costs from future regulation. Or new members self-select into voluntary initiatives because they are already well prepared for future regulations and can credibly signal their preparedness by joining

\footnotetext{
${ }^{7}$ Price shocks can trigger market reactions as well. Bushnell et al. (2013) show that the 50\% drop in the EU $\mathrm{CO}_{2}$ allowance price in 2006 affected stock prices in carbon- and electricity-intensive industries.
} 
a costly initiative. From the market's point of view, either channel would require a reassessment of the new member's future compliance costs. The degree to which these future costs are priced into their current stock prices depends on the market's current expectation of the probability of said regulation becoming reality. For simplicity, let there be two different initiatives, which differ by their type of regulatory focus. Initiative 1 consists of a permit market (anticipating regulation $a$ which would entail expected future $\operatorname{costs} c_{a}$ ). Initiative 2 prepares for a tax regime or a command and control type of $\mathrm{CO}_{2}$ regulation (anticipating regulation $b$ which would entail expected future costs $c_{b}$ ). Because both initiatives have the same agenda, we allow for the possibility of collateral side-effects in each initiative, that is, initiative 1 may also be seen as a positive signal should regulation $b$ become law (but less so than if $a$ became law), and vice versa. Membership in any initiative incurs their specific membership costs, $c_{1}$ and $c_{2}$. Finally, assume that announcing membership to an initiative that focuses on a regulation that the market actually expects is not penalized by negative stock price adjustments, so $c_{1} \leq c_{a}$ and $c_{2} \leq c_{b}$.

We cannot observe what kind of regulation the market expects at the time of the membership announcements, but we can rule out some possibilities by looking at the market's reactions for the two types of membership announcements. Let there be three distinct scenarios: 1) The market expects no regulation, 2) the market expects regulation $b$, and 3 ) the market expects regulation $a$. What would the pattern of the market reactions as measured by stock price adjustments look like in each scenario? 1) If membership announcements to either initiative are penalized with negative stock price adjustments, the market expects no regulation. ${ }^{8}$ 2) If the market expects regulation $b$, stock price adjustments for new members of initiative 2 will be non-negative. In addition, initiative 2 will trump initiative 1 in terms of stock price adjustments (where 1's adjustment may either be positive, zero, or negative, depending on whether the collateral side-effect outweighs $\left.c_{1}\right) .{ }^{9,10} 3$ ) If the market expects regulation $a$, stock price adjustments for new members of initiative 1 will be non-negative. In addition, joining initiative 1 will outperform joining initiative 2 (where 2's adjustments may either be positive, zero, or negative).

Analyzing stock price adjustments for either initiative 1 or initiative 2 exclusively cannot rule out more than one of the three scenarios at a time. A combined comparison has more explanatory power; it leaves but one scenario consistent with the observed stock price adjustments. Suppose, for example, that joining 2 yields negative stock price adjustments and joining 1 does not provoke a market reaction. 2's negative results are consistent with both scenario 1 (no regulation) and scenario 3 (regulation a). 1's non-reaction is consistent with both scenario 2 (regulation b)

\footnotetext{
${ }^{8}$ In this scenario we can also say something about the initiatives' relative costs from the ranking of the price adjustments.

${ }^{9}$ We rule out the conflating case in which the costs of being a member of initiative 1 are so small and/or its collateral side-effect is so large that initiative 1 fares better than 2 even though the market expects $b$. Otherwise everybody would always join the superior initiative 1 . The equivalent reasoning holds for initiative 1 and market expectation $a$.

${ }^{10}$ In contrast to scenario 1 we cannot say anything about the initiatives' relative costs.
} 
and scenario 3 (regulation a). The combined stock price adjustments are thus only consistent with scenario 3 (regulation a).

Phase 1 considered membership announcement effects. Let us now add a subsequent phase 2, a regulatory event. Both, one, or none of the initiatives may experience positive stock price adjustments upon a sudden increase in the likelihood of regulation, depending on whether regulation $a, b$, or some other regulation is center stage of mandatory implementation. ${ }^{11}$ This implies that the (more) fitting initiative will benefit (more).

This completes our very simple model of voluntary initiatives and market reactions as measured by stock price adjustments. The simplicity of the model has its drawbacks, however. The application is restrictive in that the model requires that the firms incur considerable costs from engaging in an initiative, costs that give rise to measurable empirical effects. Otherwise, the model is not applicable. In Section 5.3 we argue that this condition is satisfied with the CCX and the CL.

Adopting this framework to interpret our empirical results offers two advantages. First, comparing the effects for two initiatives casts light on the market's expectations about future regulation. Second, the model provides empirically testable implications. To illustrate, suppose that in phase 2 initiative 1 exhibits positive stock price adjustments during the regulatory event $a$ but initiative 2 does not. This immediately tells us that initiative 2 does not provide any collateral side-effect for regulation $a .^{12}$ More importantly, it predicts that in phase 1, announcing membership to initiative 2 entails negative stock price adjustments. This last implication is a desirable feature of our model for it introduces conditions under which it becomes empirically refutable. On the other hand, if we do find evidence that is consistent with the model, we can be more confident in our conclusions. We investigate these testable implications empirically in Section 5.3.

\section{Methodology}

Large time windows make it difficult to isolate the causal effect of an event on firm value. Brown and Warner (1980), for instance, document the problem of using monthly firm level data by illustrating that the degree of misspecification in event tests can be severe. Large time windows are not the only issue when assessing the causal effect of an event. In a well-known replication study, McWilliams and Siegel (1997) highlight the importance of accounting for confounding events at the firm level during the time of the event in question. With these two caveats in mind, this section constructs an event study by exploiting daily financial market information

\footnotetext{
${ }^{11}$ Negative reactions would not seem plausible: Initiative membership costs were priced in upon announcement, so membership in phase 2 cannot be detrimental.

${ }^{12}$ The membership announcement effects on their own would not be as telling in this matter. We could only identify such side-effects if the lower performing initiative in scenario 2 or 3 of phase 1 has non-negative returns.
} 
(stock prices) to deduce the effects of isolated events on firm value. ${ }^{13}$ In addition, we screen our observations for other, contemporaneously occurring events in order to confidently link any changes in firm value to the event in question.

The statistical inference in an event study relies on three assumptions (McWilliams and Siegel 1997): market efficiency, a lack of confounding effects during the event window, and under-/overestimation of the event. If the event in question had been fully anticipated, investors would have already had priced in its impact. Translated to our setting, the passage of the Waxman-Markey Bill had not been completely out of question. But in Section 2.1 we presented evidence that the passage of the bill had been underestimated and substantially increased the market's perceived likelihood of a mandatory emission trading system.

The measurement of the value impact of an event is carried out by calculating the so-called abnormal return. The abnormal return (AR) is the observed return minus the normal return during a specified event window, where the normal return is the return that one would expect to occur if the event had not taken place. The abnormal return $A R_{i \tau}$ is given by Eq. 1 , where $E\left(R_{i \tau} \mid X_{\tau}\right)$ is the expected return $R_{i \tau}$ given $X_{\tau}$ :

$$
A R_{i \tau}=R_{i \tau}-E\left(R_{i \tau} \mid X_{\tau}\right)
$$

In financial economics, the normal return is often modeled via the market model, which relates the return of interest $R_{i \tau}$ to the market return $R_{m \tau}$. In a nutshell, the market model isolates the fraction of the return that is associated with the market return, rendering the return of interest more informative. The parameter estimates of the market model are calculated in an Ordinary Least Squares framework on the basis of an estimation window that directly precedes the event. In addition to the market return, proxied by the value weighted average of the CRSP-COMPUSTAT sample, our specification adds Fama-French's "small minus big" (SMB) and "high minus low" (HML) factors on a daily basis as explanatory variables (Fama and French 1992; 1993). Kolari and Pynnonen (2010) illustrate that the addition of these factors achieves the highest reduction of residual cross-correlation. We call the model in Eq. 2 the 3-factor specification:

$$
R_{i \tau}=\alpha_{i}+\beta_{i 1} \cdot R_{m \tau}+\beta_{i 2} \cdot S M B_{\tau}+\beta_{i 3} \cdot H M L_{\tau}+\epsilon_{i \tau}
$$

$S M B$ in Eq. 2 denotes the daily difference of a portfolio of small and big firms and $H M L$ indicates the daily difference of a portfolio of low and high book-tomarket value firms. ${ }^{14} \epsilon_{i \tau}$ is the remaining error term after estimating $E\left(R_{i \tau} \mid X_{\tau}\right)$ and follows from $\epsilon_{i \tau}=A R_{i \tau}=R_{i \tau}-E\left(R_{i \tau} \mid X_{\tau}\right)$ via Eq. 1. In Eqs. 3 and 4 we extend the 3 -factor specification by adding two types of industry return factors, $E S r e t_{j \tau}$ and $B S r e t_{\gamma \tau}$, to control for industry effects. These extensions account for potentially industry-wide impacts of the event.

$$
\begin{aligned}
& R_{i \tau}=\alpha_{i}+\beta_{i 1} \cdot R_{m \tau}+\beta_{i 2} \cdot S M B_{\tau}+\beta_{i 3} \cdot H M L_{\tau}+\beta_{i 4} \cdot \text { ESret }_{j \tau}+\epsilon_{i \tau} \\
& R_{i \tau}=\alpha_{i}+\beta_{i 1} \cdot R_{m \tau}+\beta_{i 2} \cdot S M B_{\tau}+\beta_{i 3} \cdot H M L_{\tau}+\beta_{i 4} \cdot \text { Bret }_{\gamma \tau}+\epsilon_{i \tau}
\end{aligned}
$$

\footnotetext{
${ }^{13}$ Event studies have become an indispensable tool in econometrics. MacKinlay (1997) gives a comprehensive overview of the history, theory, and application of event studies in economics.

${ }^{14}$ Downloaded from Kenneth French's website: http://mba.tuck.dartmouth.edu/pages/faculty/ken.french/ data_library.html 
In ESret $_{j \tau}, j$ denotes one of 10 economic sectors and in $B \operatorname{Sret}_{\gamma \tau}, \gamma$ denotes one of 25 business sectors according to the Thomson Reuters Business Classification.

The event follows closely after the estimation window and is usually placed inside the so-called event window, during which the observed returns are compared to the expected ones. Because some events cannot be unambiguously dated, for example due to gradual information leakage or potential insider information, researchers often include several days around the event date $\tau=0$ into the event window. However, this comes at a cost. A longer time series of $A R_{i \tau}$ tends to increase the number of potentially confounding events and diminishes the power of the test statistic. Longer event windows are also more difficult to reconcile with the notion of market efficiency. Contrary to long-horizon event studies, the test statistics of short-horizon event studies such as ours are generally less sensitive to the benchmark model of normal returns and issues of both cross-sectional and time-series dependence of abnormal returns (Kothari and Warner 2007).

$R_{i \tau}$ is the total return index based on closing prices. Obviously the closing price of day $\tau-1$ is the opening price of day $\tau$. In event studies, coefficients from the estimation window $\left[T_{0}, T_{1}\right]$ are used in the event window $\left[T_{2}, T_{3}\right]$, where $T_{2}$ refers to the closing price on day $\tau=0$ and $T_{3}$ to the closing price on day $\tau$. An event window $[0,1]$ therefore captures the return on the day after the event day $\tau=0$. Our study analyzes two types of events, the Waxman-Markey Bill and the membership announcements. In our first and main event study, we define the Waxman-Markey event day, Friday 26 June 2009, as $\tau=0$ and set the prior estimation window to 100 trading days from $T_{0}=-99$ to $T_{1}=0$. The event day $\tau=0$, a Friday, is included in this estimation window, for two reasons: First, the vote took place at $7 \mathrm{pm}$ and therefore after the closing of the stock exchanges. Second, the issue of potential information leakage is mitigated because the outcome of the vote had been uncertain and turned out to be extremely close. In trading days, our event window $[0,1]$ is set rather narrow after the event and captures the abnormal returns on the first trading day after the event, Monday 29 June (with $T_{2}=0$ and $T_{3}=1$ ). Note, however, that the weekend is within this event window. We also employ a second, longer window $[0,2]$.

In our second and complementary event study we assess the effect of the membership announcements on firm value. To account for potential prior information leakage, we extend these narrow event windows to include the time before the day of each announcement. Recall that our study only looks at CCX announcements, as CL membership announcement effect have already been analyzed in Fisher-Vanden and Thorburn (2011). To allow for a direct comparison of our CCX to the existing CL membership announcement effects we estimate the 3-factor model as put forth in Eq. 2 and adopt Fisher-Vanden and Thorburn's three event windows [0, 1], $[-1,1]$, and $[-2,2]$. Setting the estimation window to 100 days thus sets a span from $T_{0}=-102$ to $T_{1}=-3$. In turn, the cross-sectional abnormal returns $A R_{i \tau}$ in the event window are cumulated from $T_{2}$ until $T_{3}$. This yields the cumulative abnormal returns $C A R_{i\left[T_{2}, T_{3}\right]}=\sum_{\tau=T_{2}}^{T_{3}} A R_{i \tau}$. Average CARs are obtained by averaging the CARs across the observations: $A C A R_{\left[T_{2}, T_{3}\right]}=\frac{1}{n} \sum_{i=1}^{n} C A R_{i\left[T_{2}, T_{3}\right]}$. 
The raw returns are useful for economic interpretations. Standardized returns, however, exhibit better statistical properties (Patell 1976). The scaled abnormal returns are equal to $S A R_{i \tau}=\frac{A R_{i \tau}}{S\left(A R_{i}\right)}$, where $S\left(A R_{i}\right)=\sqrt{\sigma_{\epsilon_{i}}^{2} *\left[1+x_{t}^{\prime}\left(X^{\prime} X\right)^{-1} x_{t}\right]}$ denotes the sampling error correction. The $S A R$ s can be cumulated over time, too: $C S A R_{i\left[T_{2}, T_{3}\right]}=\sum_{\tau=T_{2}}^{T_{3}} S A R_{i \tau}$. The cross sectional means of these cumulative standardized abnormal returns are equal to $A S C A R_{\left[T_{2}, T_{3}\right]}=\frac{1}{n} \sum_{i=1}^{n} C S A R_{i\left[T_{2}, T_{3}\right]}$.

Harrington and Shrider (2013) show that the presence of heterogeneous effects induces so-called event variance. Tests that are robust against cross-sectional variation in the true abnormal return should therefore be preferred. In comparison to a conventional t-test or Patell's test, the test proposed by Boehmer et al. (1991) given in Eq. 5 satisfies this condition:

$$
t_{B M P}=\frac{A C S A R \cdot \sqrt{n}}{\frac{1}{n-1} \sum_{i=1}^{n}\left(C S A R_{i}-A C S A R\right)^{2}}
$$

A particular issue for the Waxman-Markey event is clustering. In contrast to the membership announcements, the bill affected the firms simultaneously at the same point in time. One might thus question the assumption that $\epsilon_{i \tau}$ is independent and identically distributed. ${ }^{15}$ As a remedy, Kolari and Pynnonen (2010) propose a modification of the test statistic developed by Boehmer et al. (1991) that is not affected by clustering. Kolari and Pynnonen's statistic increases the cross sectional variance used by Boehmer et al. (1991) by adjusting for the average covariance of the error terms $\bar{\rho}$ during the estimation window:

$$
t_{K P}=t_{B M P} \sqrt{\frac{1-\bar{\rho}}{1+(n-1) \bar{\rho}}}
$$

We consider this test statistic to be the appropriate one for our event studies. In addition, we make use of the non-parametric generalized rank test proposed in Kolari and Pynnonen (2011) to check the robustness of our parametric tests. We choose the generalized rank test because it has better properties for testing CARs than the conventional rank test and because it is equally well-suited for testing single day abnormal returns. Finally, we would like to reiterate that the passage of the WaxmanMarkey Bill is not a complete surprise; it was partially anticipated. The abnormal returns from our main event study are therefore measuring the effect of becoming sure about the event, not the effect of being fully surprised by it. Langer and Lemoine (2020) address this issue more deeply and develop methods for recovering the market's priced-in probability of events.

\footnotetext{
${ }^{15}$ MacKinlay (1997) suggests that clustering can be accommodated in two ways. Either by a portfolio approach which allows for cross correlation of the abnormal returns, or by analyzing the abnormal returns without aggregation, e.g. by including a dummy for the event day. The latter approach has two drawbacks. Such a test will generally suffer from poor finite sample properties and has little power against reasonable alternatives.
} 


\section{Data}

This section describes our CCX and CL samples. Gans and Hintermann have kindly provided us with their CCX database and data on their selection process. We start with the same CCX database consisting of 109 members. Of these, 20 are government-affiliated; cities, states, and universities. From the remaining 89 observations, we find listings for 57 firms in the US. From these listings we drop seven firms with discontinuous price indices, a sure sign of illiquid securities. From the remaining 50 firms, seven are American Depositary Receipts (ADRs) and three are not major listings or have their book values not denominated in USD. This leaves us with 40 identified CCX member firms for the Waxman-Markey event.

We next compile a database of CL firms for the same event. Our database starts with a CL member list retrieved from the US Environmental Protection Agency as of 8 May 2009, shortly before the Waxman-Markey date. ${ }^{16}$ Of the 264 members at that time we focus on the 19 achiever and 87 setter firms. The remaining 158 socalled developer firms are by definition at a very early stage of their membership. That status is hardly an advantage in light of the Waxman-Markey Bill. ${ }^{17}$ Table 5 in the Appendix illustrates the development of the CL program over time. Of the 106 Climate Leaders with setter and achiever status, we identify 65 as being listed on a US stock market. Among these stocks, there are five illiquid equity return indices and three ADR listings. This yields an identified sample of $57 \mathrm{CL}$ firms for the WaxmanMarkey event.

The first row of Table 6 lists our identified members in both programs, 40 CCX and $57 \mathrm{CL}$ firms. We proceed by conducting a comprehensive check of confounding events happening from 26 June 2009 (Friday, the Waxman-Markey event day) through 30 June 2009 (Tuesday) for both the CCX and the CL sample. For each firm we search LexisNexis for unexpected announcements that were published in major US news outlets and which were likely to affect their market value during that time span, which fully covers our longest event window. The second row in Table 6 lists the number of confounding events for each program. For the $57 \mathrm{CL}$ firms, we identify 16 confounding events, leaving us with a final CL sample of 41 firms. For the 40 firms in the CCX sample we identify confounding events for nine firms, leaving us with a final CCX sample of 31 firms. Altogether we drop every fourth observation from our samples. An overview of our final samples for the Waxman-Markey event is given in Tables 7 and 8 . Table 7 lists our final CCX sample. Table 8 lists the final CL sample with the according membership status and whether the respective firms were charter partners.

In addition to the Waxman-Markey event - our main analysis - we are interested in membership announcement effects. Recall that Fisher-Vanden and Thorburn have already conducted this analysis for CL firms with the same methodology, so we restrict our analysis to CCX membership announcements and simply

\footnotetext{
${ }^{16}$ Obtained through www.archive.org on 20 June 2021 via web.archive.org/web/20090508120744/http:// epa.gov/climateleaders/partners/index.html

${ }^{17}$ The majority of the developer firms later on opted out of the program.
} 
incorporate Fisher-Vanden Thorburn's results into our findings. We once again start with the CCX database consisting of 109 members and apply the filters mentioned above. For the identified firms we then search both Google and LexisNexis for their membership announcement dates, resulting in the sample of 26 firms with identified dates shown in Table 7. In contrast to the Waxman-Markey event here we cumulate abnormal returns for longer event windows to account for the possibility of prior information leakage. We search for confounding events up to two days before and two days after each membership announcement. We identify six confounding events and end up with a final sample of $20 \mathrm{CCX}$ firms for our complementary membership announcement event study.

\section{Results}

This section presents the event study results for our two events. In our main analysis we first investigate the market reaction to the Waxman-Markey Bill for the CCX and CL samples. In our complementary analysis we take a look at the market reaction to membership announcements for the CCX for a direct comparison to the corresponding reaction towards CL membership announcements observed in Fisher-Vanden and Thorburn (2011). All samples have been screened for confounding events in the previous section.

\subsection{Event returns: Waxman-Markey bill}

For our main analysis, Table 1 presents descriptive statistics for the CCX and the CL samples for the Waxman-Markey Bill. The CCX sample consists of 31 firms and the CL sample contains 41 firms. The distribution of the market capitalization is positively skewed in both samples, with CL consisting of larger firms. The two samples also differ in the distribution of their sale volumes. Although CL firms have, on average, the same turnover as CCX firms, their median turnover is higher. A similar skew is visible in market-to-book values. While the average of market-to-book equity is the same in both samples, the medians indicate a proclivity for value firms in the CCX sample and for growth firms in the CL sample. Finally, the two samples differ in their industry exposure according to the Thomson Reuters Industry Classification. This would raise an issue if these industries reacted differently to the Waxman-Markey Bill. Our extended model specifications takes this into account.

We first estimate the 3 -factor model. Table 2 presents the abnormal returns and their derivatives. The results for the event windows [0,1] and [0,2] are depicted in panels $\mathrm{A}$ and $\mathrm{B}$, respectively. Consider first the short event window in panel $\mathrm{A}$. In the CCX (CL) sample, the average cumulated abnormal returns (ACAR) are $0.516 \%$ $(0.277 \%)$. Their standardized counterparts (CSAR) are lower and roughly three times as large for the CCX firms. The two-sided BMP test statistic by Boehmer et al. (1991) is highly significant for the CCX firms only. The null hypothesis of normal returns is rejected at the $1 \%$ significance level. As expected, the more conservative KP p-values according to Kolari and Pynnonen (2010) are higher (roughly 3\% for the CCX firms). Finally, the nonparametric generalized rank test also rejects the null hypothesis of normal returns for the CCX firms in the short event window. 
Table 1 Descriptive statistics for Waxman-Markey event

\begin{tabular}{llc}
\hline & CCX & CL \\
\hline Number of firms & 31 & 41 \\
Market value (MV, billion USD) & & \\
Mean MV & 17.7 & 24.1 \\
Median MV & 4.8 & 11.1 \\
Total sales (billion USD) & & \\
Mean sales & 23.2 & 23.1 \\
Median sales & 9.3 & 14.4 \\
Market-to-book equity (MEBE) & & \\
Mean MEBE & 2.1 & 2.0 \\
Median MEBE & 1.3 & 2.3 \\
Fraction of sample firms in TRBC* sector: & & \\
Basic Materials & 0.32 & 0.07 \\
Consumer Cyclicals & 0.06 & 0.20 \\
Consumer Non-Cyclicals & 0.00 & 0.07 \\
Financials & 0.03 & 0.02 \\
Healthcare & 0.03 & 0.07 \\
Industrials & 0.13 & 0.17 \\
Technology & 0.13 & 0.29 \\
Utilities & 0.29 & 0.10 \\
\hline
\end{tabular}

*TRBC: Thomson Reuters Business Classification. The market value (MV) of equity is calculated seven trading days before June 29 2009. The mnemonic of sales is WC01001 and of book equity WC03501

We now turn to the longer event window $[0,2]$ in panel B of Table 2. The ACAR of the CCX (CL) sample increases to $0.919 \%(0.412 \%)$. This suggests that the market kept incorporating the new information on the second trading day after the event. The abnormal returns remain statistically significant for the CCX firms, at an even stronger level. The CL firms, on the other hand, do not seem to exhibit significant abnormal returns in this longer event window, either.

The results of the 3-factor model suggest that the market valued membership in the CCX initiative but not in the CL initiative when the Waxman-Markey Bill passed. But recall that the CCX and CL samples differ in their sector distribution. This raises inference issues in our analysis because the review of the empirical evidence in Section 2 suggests that some sectors exhibit a higher vulnerability to regulatory shocks. In our case, industry-specific effects could stem from two sources. For one, firms from industries that are generally positively affected by a mandatory emission cap-and-trade system could be more likely to opt into voluntary emission reduction programs. Second, the Waxman-Markey event took place in the midst of an economic recession, a recession which did not affect all industries alike. In order to isolate the CCX and CL membership effect during the Waxman-Markey event from such 
Table 2 3-factor model

\begin{tabular}{|c|c|c|}
\hline & $\mathrm{CCX}$ & $\mathrm{CL}$ \\
\hline \multicolumn{3}{|c|}{ Panel A: event window $[0,1]$} \\
\hline ACAR & 0.516 & 0.277 \\
\hline ACSAR & 0.308 & 0.119 \\
\hline BMP t-statistic & 2.849 & 1.322 \\
\hline BMP p-val & 0.008 & 0.194 \\
\hline KP t-statistic & 2.240 & 0.893 \\
\hline KP p-val & 0.032 & 0.377 \\
\hline GRank Test & 2.423 & 1.371 \\
\hline GRank p-val & 0.017 & 0.174 \\
\hline Nr. of Observations & 31 & 41 \\
\hline \multicolumn{3}{|c|}{ Panel B: event window $[0,2]$} \\
\hline ACAR & 0.919 & 0.412 \\
\hline ACSAR & 0.557 & 0.151 \\
\hline BMP t-statistic & 3.545 & 1.128 \\
\hline BMP p-val & 0.001 & 0.266 \\
\hline KP t-statistic & 2.787 & 0.762 \\
\hline KP p-val & 0.009 & 0.451 \\
\hline GRank Test & 2.676 & 1.088 \\
\hline GRank p-val & 0.009 & 0.279 \\
\hline Nr. of Observations & 31 & 41 \\
\hline
\end{tabular}

ACAR \& ACSAR in \%. There is a 100 days estimation window prior to the event on 26 June 2009. Event window[0,1] captures the abnormal returns on day 29 June 2009 and event window[0,2] adds 30 June 2009. The BMP test (Boehmer et al. 1991) is an extension of Patell (1976) and robust to event induced variance. The KP test (Kolari and Pynnonen 2010) is adjusting the BMP test for cross sectional correlation. In our samples the average correlation of abnormal returns $\bar{\rho}$ is: $\bar{\rho}_{c l \& c c x}=0.022, \bar{\rho}_{c c x}=0.020, \bar{\rho}_{c l}=$ 0.029 . The non-parametric GRank test is the generalized rank test for cumulated returns from Kolari and Pynnonen (2011)

overarching trends, we proceed by controlling for industry-specific confoundings by extending the 3 -factor specification model with both economic and (to reach a deeper level) business sector returns.

First the economic sector extension. We incorporate industry return factors from 10 economic sectors. For each security $i$ in sector $j$ we add to the 3 -factor model the economic sector return $j$ as defined in Eq. 3. Table 9 summarizes the results of this second specification. It turns out that economic sector returns explain a part of the positive effects estimated in the 3-factor specification. The CCX sample, keeps showing significant abnormal returns, in particular for the longer event window $(0.86 \%)$ with significant results across all tests at around the $1 \%$ level. The ACARs are lower, 
however. Our second model specification therefore indicates that sectoral effects have been at work during the Waxman-Markey event.

To further check the robustness of the economic sector results in Table 9, we extend the 3-factor specification by adding to each security $i$ in business sector $\gamma$ the business sector return BUSret $_{\gamma}$. In contrast to 10 economic sectors, this differentiation is more fine-grained by controlling for 25 business sectors. The event study results of this third and strictest model specification, given by Eq. 4, are shown in Table 3. The pattern reinforces the direction of the previous specification with 10 economic sectors. There remains decent evidence of abnormal returns for the longer event window in panel $\mathrm{B}$ at $0.815 \%$ with p-values below the $10 \%$ level for the BMP

Table 3 4-factor business sector model

\begin{tabular}{|c|c|c|}
\hline & $\mathrm{CCX}$ & $\mathrm{CL}$ \\
\hline \multicolumn{3}{|c|}{ Panel A: event window $[0,1]$} \\
\hline ACAR & -0.241 & -0.046 \\
\hline ACSAR & 0.045 & -0.004 \\
\hline BMP t-statistic & 0.379 & -0.044 \\
\hline BMP p-val & 0.707 & 0.965 \\
\hline KP t-statistic & 0.390 & -0.042 \\
\hline KP p-val & 0.699 & 0.967 \\
\hline GRank Test & 0.479 & 0.287 \\
\hline GRank p-val & 0.633 & 0.775 \\
\hline Nr. of Observations & 31 & 41 \\
\hline \multicolumn{3}{|c|}{ Panel B: event window $[0,2]$} \\
\hline ACAR & 0.815 & 0.334 \\
\hline ACSAR & 0.287 & 0.023 \\
\hline BMP t-statistic & 1.739 & 0.172 \\
\hline BMP p-val & 0.092 & 0.865 \\
\hline KP t-statistic & 1.786 & 0.164 \\
\hline KP p-val & 0.084 & 0.871 \\
\hline GRank Test & 1.605 & 0.427 \\
\hline GRank p-val & 0.112 & 0.671 \\
\hline Nr. of Observations & 31 & 41 \\
\hline
\end{tabular}

ACAR \& ACSAR in \%. There is a 100 days estimation window prior to the event on 26 June 2009. Event window[0,1] captures the abnormal returns on day 29 June 2009 and event window[0,2] adds 30 June 2009. The BMP test (Boehmer et al. 1991) is an extension of Patell (1976) and robust to event induced variance. The KP test (Kolari and Pynnonen 2010) is adjusting the BMP test for cross sectional correlation. In our samples the average correlation of abnormal returns $\bar{\rho}$ is: $\bar{\rho}_{c l \& c c x}=-0.000, \bar{\rho}_{c c x}=-0.002, \bar{\rho}_{c l}=$ 0.002 . The non-parametric GRank test is the generalized rank test for cumulated returns from Kolari and Pynnonen (2011) 
and the KP test. This average effect does not seem to be driven by outliers: In that 2 day event window the CCX sample experienced 24 positive and 7 negative cumulative returns (and the CL sample 26 positive and 15 negative returns, respectively). In the short event window in panel A, however, controlling for business sectors renders the statistical significance for CCX firms non-significant. ${ }^{18}$

In the same business sector specification, let us take a closer look at the longer event window for the CCX sample (in panel B). The CARs are positively skewed, with a substantially higher mean than median value. This holds true for the standardized CARs as well. The previous two specifications have shown consistently lower p-values for the BMP test in comparison to the KP test. This order has now switched. This switch can be explained by the average correlation of the abnormal returns $\bar{\rho}$, which has become slightly negative. The third specification thus suggests that business sector effects explain an additional part of the positive abnormal returns found in the previous two specifications. Further indication that controlling for sectoral effects has increased the explanatory power is reflected by decreasing correlation of the abnormal returns $\bar{\rho}$ (see the notes in the according tables).

Taken together, our results suggest that in the wake of the Waxman-Markey event CCX firms profited from the increased threat of regulation in addition to being overrepresented in favorable sectors. In contrast, CL membership did not seem to provide value during that event.

\subsection{Event returns: CCX membership announcement}

Fisher-Vanden and Thorburn have shown that new CL firms lost considerable market value upon announcing their memberships. In our complementary analysis here we investigate the same reaction towards CCX membership announcements. After screening for confounding events in Section 4 we have identified a final sample of 20 firms with $\mathrm{CCX}$ engagement declaration dates, ranging from the founding members in 2003 up to the last announcements in 2008. The Waxman-Markey event took place at a single point in time and had potential ramifications for the entire macroeconomy, simultaneously affecting different industries differently. Such industry-specific effects are not a concern with the membership announcements analyzed here, which are scattered over several years.

For this event study we thus confine ourselves to estimating the 3-factor specification. In contrast to the Waxman-Markey event, however, information leakage poses a potential problem. To address the possibility that insider information had affected stock prices before the firms' public statements, here we extend the event window symmetrically around the announcement dates. In addition to calculating the cumulated abnormal returns over the short window $[0,1]$ we add two longer windows,

\footnotetext{
${ }^{18}$ One could argue that there could have been already an upward adjustment in the assessed probability of the Bill passing in the run-up to Friday evening's vote. Press articles do not paint a clear picture, however, and the Intrade prediction market data discussed in Footnote 4 do not show a change in predicted probability in the days prior to the vote - only on the days after. In untabulated results, we tested the leakage possibility empirically. If there had been an upward adjustment, we would expect even stronger abnormal returns if Friday was included in the event window. Including Friday, however, renders the results for the CCX firms statistically non-significant for the 4-factor business model, possibly due to the reduction of the power of the test statistic in longer event windows (MacKinlay 1997).
} 
$[-1,1]$ and $[-2,2]$. This also makes for a direct comparison with the CL membership announcement event windows chosen by Fisher-Vanden and Thorburn.

Table 4 presents the abnormal return estimates for the CCX membership announcements. Over the short window, both the ACAR and the ACSAR are slightly positive. This changes when expanding the event windows, with the longest window exhibiting negative returns across the board. However, none of the results are statistically significant. All test statistics are well above conventional significance levels and cannot reject the null hypothesis of normal returns upon the firms announcing their CCX memberships.

This result qualifies the findings in Gans and Hintermann, who infer a strongly positive market reaction upon CCX membership accouncements. Though qualifying, it still stands in contrast with the corresponding CL analysis in Fisher-Vanden and Thorburn: Newly announced engagement in the CL initiative was punished with negative abnormal returns of $-1 \%$ for ACAR $[-1,1]$ and $-1.5 \%$ for ACAR[-2,2].

\subsection{Discussion}

The theoretical framework put forth in Section 2.4 lets us connect the two events and can shed some light on market expectations. We argue that the CCX and the CL satisfy the model assumption of the cost of the initiative being tangible.

Table 4 Three event windows based on the 3-factor model

\begin{tabular}{llll}
\hline & {$[0,1]$} & {$[-1,1]$} & {$[-2,2]$} \\
\hline ACAR & 0.182 & -0.191 & -0.294 \\
CAR Median & 0.456 & -0.272 & -0.425 \\
ACSAR & 0.215 & 0.196 & 0.082 \\
CSAR Median & 0.182 & -0.127 & -0.165 \\
Patell t-statistic & 0.950 & 0.865 & 0.363 \\
Patell p-val & 0.345 & 0.389 & 0.717 \\
BMP t-statistic & 0.602 & 0.361 & 0.147 \\
BMP p-val & 0.549 & 0.719 & 0.883 \\
KP t-statistic & 0.556 & 0.334 & 0.136 \\
KP p-val & 0.579 & 0.739 & 0.892 \\
GRank Test & 1.045 & 0.425 & 0.224 \\
GRank p-val & 0.299 & 0.672 & 0.823 \\
Nr. of Observations & 20 & 20 & 20 \\
\hline
\end{tabular}

CAR \& CSAR in \%. The 3-factor model parameters are estimated during an estimation window of 100 days. The BMP test (Boehmer et al. 1991) is an extension of Patell (1976), robust to event induced variance. Kolari and Pynnonen (2010) (KP) extend the BMP test, adjusting for cross sectional correlation. The average correlation of abnormal returns $\bar{\rho}$ in our sample is $\bar{\rho}=0.009$ The GRank test is the generalized rank test for cumulated abnormal returns from Kolari and Pynnonen (2011) 
Fisher-Vanden and Thorburn infer that "investors are interpreting membership in Climate Leaders and subsequent pledges to reduce greenhouse gas emissions as imposing significant costs on the firm" because of the significant drop in stock price upon announcing their membership in the initiative (p. 431). Membership in the CCX, too, entailed significant costs in terms of emission reductions. From 2003 to 2006 members had to cut their emissions annually by $1 \%$ below their baseline average as defined from 1998 to 2001. From 2007 to 2010, an additional of $0.5 \%$ was required to achieve an overall target of $6 \%$ below 1998-2001 levels by 2010 . The emission baselines and emission reports were verified independently. ${ }^{19}$

Our main event study in Section 5.1 shows that CCX members enjoyed a positive market reaction upon the regulatory event, the Waxman-Markey Bill. It also shows that being in the CL initiative did not provoke a measurable market reaction. This suggests that the market only deemed members of the CCX initiative having an economic advantage in light of the increased likelihood of federal carbon legislation. This implication of the model is consistent with the pattern of the prior membership announcement effects, where we observed no market reaction for joining the CCX initiative (Section 5.2). Announcing membership in the CL initiative, however, was found to provoke a negative market reaction according to Fisher-Vanden and Thorburn.

The combined pattern only fits scenario 3 from the theoretical framework, where the market expected a permit regulation. In that scenario, the initiative devoted to a permit market exhibits non-negative returns while faring better than the other initiative. This suggests that the market had already expected a permit regulation prior to the Waxman-Markey event, and that the CCX members had made a sensible choice by joining. The lack of a measurable market reaction upon CCX announcements suggests that the initiative's cost and the expected benefit of being a member balanced each other in times of lower regulatory pressure. It was during the Waxman-Markey event when the CCX could really shine. Firms joining the CCX had apparently been acting in the interest of their shareholders. Membership in the CL initiative, on the other hand, offered no apparent advantage during the Waxman-Markey Bill, a conclusion that is consistent with the negative reaction firms encountered upon their CL membership announcements.

The event study results tell us yet more. In terms of the model, the lack of a CL reaction upon the Waxman-Markey Bill suggests that the market judged that members of the CL initiative harbored no collateral benefit for the expected carbon market. The model thus predicts the CL announcement effects to be negative, a prediction which is empirically verified. If they were neutral or positive, our model would have been refuted.

The negative market reaction raises the question why firms had acted against their investors' interest and joined the CL initiative. Fisher-Vanden and Thorburn present an explanation. They found that firms joining the CL initiative are more likely to have weak corporate governance structures and more likely to have a higher

\footnotetext{
${ }^{19}$ https://web.archive.org/web/20161227130746/http://co2offsetresearch.org/policy/CCX.html, visited on 20 June 2021
} 
number of shareholder resolutions directed at climate change. It seems that the corporate governance structure of these firms was giving less weight to shareholder value maximization than it did to other stakeholder interests. Fisher-Vanden and Thorburn conclude that this combination of institutional pressure and less shareholder oversight gave CL firms more discretionary leeway in their decision to join. That conclusion would explain why, in our model, CL firms did not abide by the market's expectations and ignored shareholder value. On that note, recall that the EPA made the CL initiative palatable to firms by highlighting high level recognition via participation in meetings, public outreach, and press events. These amenities for firm executives might help explain why the interests of the market and the weakly governed CL firms did not align.

\section{Conclusion}

This paper pieces together a puzzle by extending, rectifying, and combining existing findings to outline a bigger picture of the perceived market value of membership in voluntary corporate climate initiatives. We establish a direct comparison of two distinct initiatives for two separate events. First, we compare how membership in the CCX and CL initiatives was valued by the market when push came to shove with the Waxman-Markey Bill, which intended to establish a mandated carbon market with tradeable emission certificates in the US. Second, we juxtapose the prior market reactions towards the CCX and CL membership announcements.

In our main event study, the estimated market reaction to the Waxman-Markey Bill indicates a positive value correction for CCX firms. The most conservative estimate puts the positive abnormal return for CCX firms at roughly $0.8 \%$. This suggests that the market considered membership in that initiative an advantageous signal for a carbon market. Membership in the CL initiative, on the other hand, did not provoke a measurable market reaction. Results from different model specifications suggest that the Waxman-Markey Bill was expected to affect different industries differently. Failing to account for such industry effects would overestimate the value of membership in the CCX. On the other hand, failing to acknowledge that the passing of the Waxman-Markey Bill only increased the probability of the implementation of a cap-and-trade system would underestimate the value of membership measured in our event study. Put differently, the $0.8 \%$ do not reflect the full market valuation of CCX membership; they describe the expected added value that stems from the change in probability of implementation due to the bill passing in the House, a passing that was partially anticipated but not fully expected. In this sense, the $0.8 \%$ constitute a lower bound of the valuation (Langer and Lemoine 2020).

In our complementary event study, we investigate and compare the earlier market reactions towards the preceding membership announcements to these initiatives. In their event study, Fisher-Vanden and Thorburn (2011) found significant negative effects when firms announced their CL engagement. In contrast, our results cannot reject a neutral market reaction for CCX membership announcements.

Taken together, the pattern of the market reactions for the two initiatives and the two events paints a rounded picture. When applied to our model, the pattern 
is consistent with the hypothesis that membership in the CL initiative was never deemed useful for a cap-and-trade system, and that the market had been entertaining expectations for such a carbon market all along.

Our findings suggest that the market can consider membership in fitting voluntary initiatives a worthwhile venture if corresponding regulation is foreshadowing. Existing evidence suggests that this depends on the type of regulation. Welfens and Celebi (2020) present a concrete channel for higher firm value in a cap-and-trade system via a surplus of tradeable emission certificates for certain firms. Any excess supply of certificates becomes part of the firm's assets and thus its equity, which raises the market value of that firm. In our case, this is consistent with the market's assessment for the CCX firms' advantageous position in light of the Waxman-Markey Bill.

Policy makers and investors thus need to consider the potential impact that the introduction of an equity-based mechanism such as a cap-and-trade system can have on the financial and subsequently the real economy. This impact goes beyond direct effects. Over time, a rising price of emission certificates tends to incentivize innovation that advances decarbonisation. De Haas and Popov (2019a, 2019b) point in that direction. They contend that when it comes to advance decarbonisation, some financial markets seem to fare better. De Haas and Popov provide evidence that favors equity-based instead of credit-based mechanisms for stimulating innovation that leads to the adoption of greener technologies. This aligns with the findings in this paper and is a crucial policy insight. The UN Climate Change Conferences have for some years been emphasizing the key role of financial markets to achieve the Paris Agreement goals.

\section{Appendix A: Figures and tables}

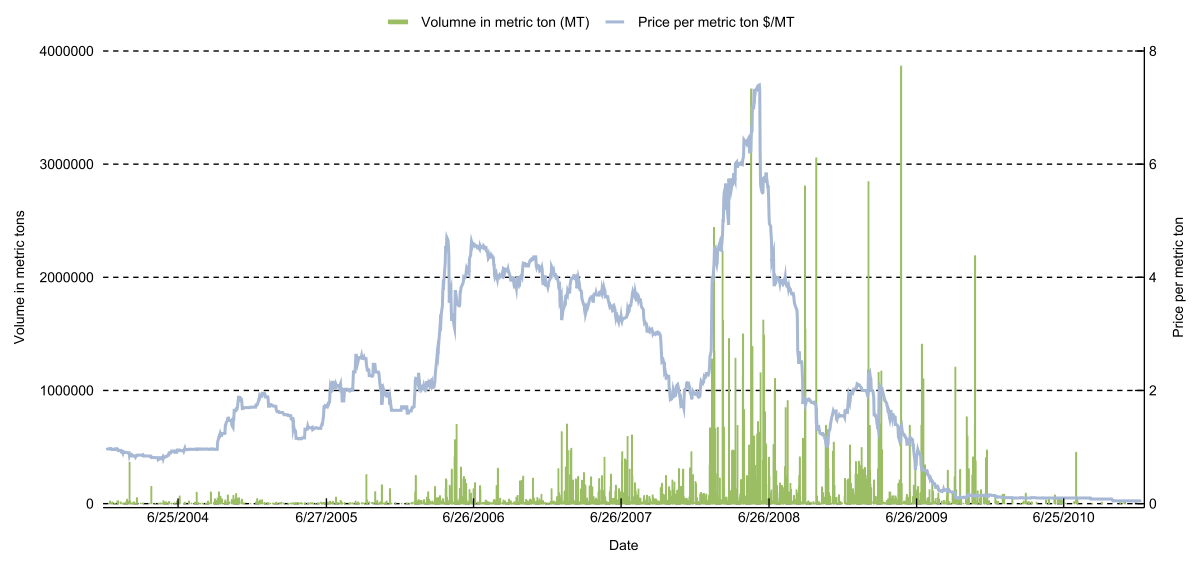

Source: Intercontinental Exchange (ICE)

Fig. 1 CCX Daily Average Volume (metric ton) and settlement price 
Table 5 Climate leader membership development

\begin{tabular}{lllll}
\hline Date & \# Firms & Achievers & Setters & Developers \\
\hline 28.03 .2008 & 162 & 11 & 69 & 82 \\
21.05 .2008 & 172 & 11 & 69 & 92 \\
03.01 .2009 & 249 & 18 & 85 & 146 \\
08.05 .2009 & 264 & 19 & 87 & 158 \\
$01.08 .2010 *$ & 191 & 26 & 93 & 72 \\
13.02 .2011 & 183 & 32 & 100 & 51 \\
\hline
\end{tabular}

* Retrieved on 20 June 2021 from:

https://web.archive.org/web/20150512000103/https://www.epa.gov/climateleadership/documents/ directory.pdf

All other dates are also from lists retrieved from www.archive.org

Table 6 Number of firms in samples

\begin{tabular}{|c|c|c|c|}
\hline & \multicolumn{2}{|c|}{ Waxman-Markey Event } & \multirow{2}{*}{$\begin{array}{l}\text { Membership Announcements } \\
\text { CCX }\end{array}$} \\
\hline & $\mathrm{CCX}$ & CL & \\
\hline Identified* ${ }^{*}$ & 40 & 57 & 26 \\
\hline Confounding events & 9 & 16 & 6 \\
\hline Final sample & 31 & 41 & 20 \\
\hline
\end{tabular}

* Identified firms are neither illiquid nor ADRs 
Table 7 Chicago climate exchange firms (CCX) and event samples

\begin{tabular}{|c|c|c|c|}
\hline \multirow{2}{*}{$\frac{\text { Firm name }}{\text { Abbott Laboratories }}$} & \multicolumn{2}{|c|}{ Sample membership* } & \multirow{2}{*}{$\begin{array}{l}\text { Announcement Date } \\
02 / 11 / 2008\end{array}$} \\
\hline & MA & & \\
\hline Agrium U.S. Inc. & & $\mathrm{W} \& \mathrm{M}$ & \\
\hline Alliant Energy Corporate Services Inc. & & $\mathrm{W} \& \mathrm{M}$ & \\
\hline American Electric Power ${ }^{\dagger}$ & MA & W\&M & $01 / 16 / 2003$ \\
\hline Avista Corporation & MA & W\&M & $11 / 05 / 2007$ \\
\hline Bank of America Corporation & & $\mathrm{W} \& \mathrm{M}$ & \\
\hline Baxter International Inc. ${ }^{\dagger}$ & MA & $\mathrm{W} \& \mathrm{M}$ & $01 / 16 / 2003$ \\
\hline Boise Paper Holdings, LLC & MA & $\mathrm{W} \& \mathrm{M}$ & $07 / 24 / 2008$ \\
\hline CLECO Corporation & & $\mathrm{W} \& \mathrm{M}$ & \\
\hline Central Vermont Public Service & MA & $\mathrm{W} \& \mathrm{M}$ & $08 / 02 / 2005$ \\
\hline Dow Corning & & $\mathrm{W} \& \mathrm{M}$ & \\
\hline DTE Energy Inc & MA & $\mathrm{W} \& \mathrm{M}$ & $06 / 12 / 2007$ \\
\hline DuPont $^{\dagger}$ & & $\mathrm{W} \& \mathrm{M}$ & \\
\hline Eastman Kodak Company & & $\mathrm{W} \& \mathrm{M}$ & \\
\hline FMC Corporation & & $\mathrm{W} \& \mathrm{M}$ & \\
\hline Ford Motor Company ${ }^{\dagger}$ & & $\mathrm{W} \& \mathrm{M}$ & \\
\hline Genon Energy Inco. & MA & & 05/30/2007 \\
\hline Green Mnt.Power Corp. & MA & & $10 / 07 / 2004$ \\
\hline Intel Corporation & MA & $\mathrm{W} \& \mathrm{M}$ & 04/10/2007 \\
\hline Interface, Inc. & MA & $\mathrm{W} \& \mathrm{M}$ & $11 / 08 / 2004$ \\
\hline IBM & MA & $\mathrm{W} \& \mathrm{M}$ & $12 / 09 / 2003$ \\
\hline International Paper ${ }^{\dagger}$ & & $\mathrm{W} \& \mathrm{M}$ & \\
\hline Knoll, Inc. & MA & $\mathrm{W} \& \mathrm{M}$ & $11 / 02 / 2006$ \\
\hline 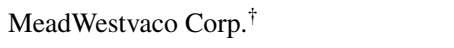 & MA & $\mathrm{W} \& \mathrm{M}$ & $01 / 16 / 2003$ \\
\hline Mirant Corporation & & $\mathrm{W} \& \mathrm{M}$ & \\
\hline Motorola, Inc..$^{\dagger}$ & & $\mathrm{W} \& \mathrm{M}$ & \\
\hline Neenah Paper Incorporated & MA & W\&M & $05 / 24 / 2007$ \\
\hline Nrg Energy Inco. & MA & & 05/30/2007 \\
\hline Plum Creek Timber Company, Inc. & & $\mathrm{W} \& \mathrm{M}$ & \\
\hline PSEG Energy Resources \& Trade LLC & & $\mathrm{W} \& \mathrm{M}$ & \\
\hline Puget Energy Inco. & MA & & $02 / 23 / 2007$ \\
\hline Safeway Incorporated & MA & & $09 / 27 / 2006$ \\
\hline Steelcase Inc. & & $\mathrm{W} \& \mathrm{M}$ & \\
\hline TECO Energy, Inc. & & $\mathrm{W} \& \mathrm{M}$ & \\
\hline Temple-Inland Inc ${ }^{\dagger}$ & MA & W\&M & $01 / 16 / 2003$ \\
\hline United Technologies Corporation & & $\mathrm{W} \& \mathrm{M}$ & \\
\hline Waste Management Inc..$^{\dagger}$ & MA & $\mathrm{W} \& \mathrm{M}$ & $01 / 16 / 2003$ \\
\hline
\end{tabular}

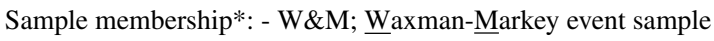

- MA; Membership Announcement sample

${ }^{\dagger}$ charter member 
Table 8 Sample of climate leader firms (CL) for Waxman-Markey event

\begin{tabular}{|c|c|c|c|}
\hline Firm name & CL status* & Charter partner & Reduction region \\
\hline $3 \mathrm{M}$ & achievers & & US GHG \\
\hline Advanced Micro Devices, Inc. & achievers & charter partner & global GHG \\
\hline Agilent Technologies & setters & & global GHG \\
\hline American Electric Power & achievers & & US GHG \\
\hline Applied Materials, Inc. & setters & & global GHG \\
\hline Bank of America Corporation & setters & & US GHG \\
\hline Baxter International Inc. & achievers & charter partner & US GHG \\
\hline Best Buy Co., Inc. & setters & & US GHG \\
\hline Calpine & setters & & US GHG \\
\hline Campbell Soup Company & setters & & US GHG \\
\hline Caterpillar Inc. & achievers & & global GHG \\
\hline Cisco Systems, Inc. & setters & & global GHG \\
\hline Cummins Inc. & setters & & global GHG \\
\hline Dell Inc. & setters & & global GHG \\
\hline DuPont Company & setters & & global GHG \\
\hline Eastman Kodak Company & setters & charter partner & global GHG \\
\hline Ecolab, Inc. & setters & & US GHG \\
\hline EMC Corporation & setters & & US GHG \\
\hline Fairchild Semiconductor & setters & & US GHG \\
\hline Hasbro, Inc. & achievers & charter partner & US GHG \\
\hline Intel Corporation & setters & & global GHG \\
\hline Interface, Inc. & setters & charter partner & US GHG \\
\hline IBM Corporation & achievers & charter partner & global GHG \\
\hline International Paper & setters & charter partner & US GHG \\
\hline Johnson Controls, Inc. & setters & & US GHG \\
\hline LSI Corporation & setters & & US GHG \\
\hline Marriott International, Inc. & setters & & US GHG \\
\hline Merck \& Co., Inc. & setters & & global GHG \\
\hline Millipore Corporation & setters & & global GHG \\
\hline Coors Brewing Company & setters & & US GHG \\
\hline FPL Group, Inc. & achievers & charter partner & US GHG \\
\hline NVIDIA Corporation & setters & & US GHG \\
\hline Owens Corning & setters & & US GHG \\
\hline PepsiCo & setters & & US GHG \\
\hline PPG Industries, Inc. & setters & & global GHG \\
\hline PSEG & setters & charter partner & US GHG \\
\hline
\end{tabular}


Table 8 (continued)

\begin{tabular}{llll}
\hline Firm name & CL status* & Charter partner & Reduction region \\
\hline Staples, Inc. & setters & charter partner & US GHG \\
Steelcase Inc. & setters & US GHG \\
Gap, Inc. & setters & US GHG \\
United Technologies Corporation & achievers & global GHG \\
Xerox Corporation & achievers & global GHG \\
\hline
\end{tabular}

Status of Climate Leader member with regard to emission reduction pledge

Table 9 4-factor economic sector model

\begin{tabular}{|c|c|c|}
\hline & $\mathrm{CCX}$ & $\mathrm{CL}$ \\
\hline \multicolumn{3}{|c|}{ Panel A: event window $[0,1]$} \\
\hline ACAR & 0.223 & -0.006 \\
\hline ACSAR & 0.185 & -0.001 \\
\hline BMP t-statistic & 1.675 & -0.007 \\
\hline BMP p-val & 0.104 & 0.994 \\
\hline KP t-statistic & 1.728 & -0.006 \\
\hline KP p-val & 0.094 & 0.995 \\
\hline GRank Test & 1.964 & 0.453 \\
\hline GRank p-val & 0.052 & 0.652 \\
\hline Nr. of Observations & 31 & 41 \\
\hline \multicolumn{3}{|c|}{ Panel B: event window $[0,2]$} \\
\hline ACAR & 0.860 & 0.363 \\
\hline ACSAR & 0.451 & 0.028 \\
\hline BMP t-statistic & 2.848 & 0.206 \\
\hline BMP p-val & 0.008 & 0.838 \\
\hline KP t-statistic & 2.939 & 0.178 \\
\hline KP p-val & 0.006 & 0.860 \\
\hline GRank Test & 2.640 & 0.444 \\
\hline GRank p-val & 0.010 & 0.658 \\
\hline Nr. of Observations & 31 & 41 \\
\hline
\end{tabular}

ACAR \& ACSAR in \%. There is a 100 estimation window prior to the event on 26 June 2009. Event window[0,1] captures the abnormal returns on day 29 June 2009 and event window[0,2] adds 30 June 2009. The BMP test (Boehmer et al. 1991) is an extension of Patell (1976) and robust to event induced variance. The KP test (Kolari and Pynnonen 2010) is adjusting the BMP test for cross sectional correlation. In our samples the average correlation of abnormal returns $\bar{\rho}$ is: $\bar{\rho}_{c l} \& c c x=0.003, \bar{\rho}_{c c x}=-0.002, \bar{\rho}_{c l}=$ 0.009 . The non-parametric GRank test is the generalized rank test for cumulated returns from Kolari and Pynnonen (2011) 
Acknowledgements We are grateful to Esther Blanco, Filippo Lechthaler, Peter Schmidt, and two anonymous referees for their highly constructive comments. We appreciate that Beat Hintermann provided us with the data he and Will Gans used for their study. We are also thankful for discussions with participants at the RESEC Seminar at ETH Zurich, the Swiss Society of Economics and Statistics conference, the European Association of Environmental and Resource Economists conference, and the sub-theme Sustainable Development and Financial Markets at the European Group for Organizational Studies colloquium. Financial support from the Commission for Technology and Innovation of the Swiss Confederation is gratefully acknowledged.

Funding Open Access funding provided by ETH Zurich.

Open Access This article is licensed under a Creative Commons Attribution 4.0 International License, which permits use, sharing, adaptation, distribution and reproduction in any medium or format, as long as you give appropriate credit to the original author(s) and the source, provide a link to the Creative Commons licence, and indicate if changes were made. The images or other third party material in this article are included in the article's Creative Commons licence, unless indicated otherwise in a credit line to the material. If material is not included in the article's Creative Commons licence and your intended use is not permitted by statutory regulation or exceeds the permitted use, you will need to obtain permission directly from the copyright holder. To view a copy of this licence, visit http://creativecommons.org/licenses/by/4.0/.

\section{References}

Betzer A, Doumet M, Rinne U (2013) How policy changes affect shareholder wealth: the case of the Fukushima Dai-ichi nuclear disaster. Appl Econ Lett 20(8):799-803

Blacconiere WG, Northcut WD (1997) Environmental information and market reactions to environmental legislation. J Acc Audit Financ 12(2):149-178

Blacconiere WG, Patten DM (1994) Environmental disclosures, regulatory costs, and changes in firm value. J Account Econ 18(3):357-377

Boehmer E, Musumeci J, Poulsen AB (1991) Event-study methodology under conditions of event-induced variance. J Financ Econ 30:253-72

Bowen RM, Castanias RP, Daley LA (1983) Intra-industry effects of the accident at three mile island. J Financ Quantit Anal 18(1):87

Brown SJ, Warner JB (1980) Measuring security price performance. J Financ Econ 8:205-258

Bushnell BJB, Chong H, Mansur ET (2013) Profiting from regulation: evidence from the european carbon market. Am Econ J Econ Policy 5(4):78-106

De Haas R, Popov A (2019a) Finance and carbon emissions. European Central Bank Working Paper Series 2318

De Haas R., Popov A (2019b) Finance and decarbonisation: why equity markets do it better. Res Bull 64

Fama EF, French KR (1992) The cross-section of expected stock returns. J Financ 47(2):427

Fama EF, French KR (1993) Common risk factors in the returns on stocks and bonds. J Financ Econ 33(1):3-56

Financial Times (2010) End of US carbon trading looms

Fisher-Vanden K, Thorburn KS (2011) Voluntary corporate environmental initiatives and shareholder wealth. J Environ Econ Manag 62(3):430-445

Fleckinger P, Glachant M (2011) Negotiating a voluntary agreement when firms self-regulate. J Environ Econ Manag 62(1):41-52

Freedman M, Patten DM (2004) Evidence on the pernicious effect of financial report environmental disclosure. Account Forum 28(1):27-41

Gans W, Hintermann B (2013) Market effects of voluntary climate action by firms: evidence from the chicago climate exchange. Environ Resour Econ 55(2):291-308

Harrington SE, Shrider DG (2013) All events induce variance : analyzing abnormal returns when effects vary across firms firms. J Financ Quant Anal 42(1):229-256

Hill J, Schneeweis T (1983) The effect of three mile island on electric utility stock prices: a note. J Financ 38(4):1285-1292 
Kahn S, Knittel CR (2003) The impact of the clean air act amendments of 1990 on electric utilities and coal mines : Evidence from the stock market

Khanna M (2002) Non-mandatory approaches to environmental protection. J Econ Surv 15(3):291-324

Kim E-H, Lyon TP (2011) When does institutional investor activism increase shareholder value?: The Carbon Disclosure Project. The B.E. J Econ Anal Policy 11(1) Article 50

Kolari JW, Pynnonen S (2010) Event study testing with cross-sectional correlation of abnormal returns. Rev Financ Stud 23(11):3996-4025

Kolari JW, Pynnonen S (2011) Nonparametric rank tests for event studies. J Empir Financ 18(5):953-971

Kothari SP, Warner JB (2007) Econometrics of event studies. In: Eckbo BE (ed) Handbook of empirical corporate finance, Chapter 1. 1st edn., North Holland, pp 3-36

Langer A, Lemoine D (2020) What were the odds? Estimating the market's probability of uncertain events. NBER Working Paper Series 28265

Lyon TP, Maxwell JW (2003) Self-regulation, taxation and public voluntary environmental agreements. J Public Econ 87(7-8):1453-1486

Lyon TP, Maxwell JW (2008) Corporate social responsibility and the environment: a theoretical perspective. Rev Environ Econ Policy 2(2):240-260

MacKinlay AC (1997) Event studies in economics and finance. J Econ Lit 35(1):13-39

McWilliams A, Siegel D (1997) Event studies in management research: theoretical and empirical issues. Acad Manag J 40(3):626-657

Meng KC (2017) Using a free permit rule to forecast the marginal abatement cost of proposed climate policy. Am Econ Rev 107(3):748-784

Patell JM (1976) Corporate forecasts of earnings per share and stock price behavior : empirical tests. J Account Res 14(2):246-276

Portney PR (2008) The (Not So) new corporate social responsibility: an empirical perspective. Rev Environ Econ Policy 2(2):261-275

Snowberg E, Wolfers J, Zitzewitz E (2011) How prediction markets can save event studies. NBER Work Pap Ser 16949:18-34

Telle K (2013) Monitoring and enforcement of environmental regulations. Lessons from a natural field experiment in Norway. J Public Econ 99:24-34

Tonkonogy B, Oliva MJ (2007) Introduction to the climate leaders program : Introduction for new partners. climate leaders partners meeting, December 3, 2007. Number December

Welfens PJ, Celebi K (2020) CO2 Allowance Price Dynamics and Stock Markets in EU Countries: Empirical Findings and Global CO2-Perspectives. EIIW Discussion Paper 267

Publisher's note Springer Nature remains neutral with regard to jurisdictional claims in published maps and institutional affiliations. 